Article

\title{
Efficiency of Different Superplasticizers and Retarders on Properties of 'One-Part' Fly Ash-Slag Blended Geopolymers with Different Activators
}

\author{
Shin Hau Bong, Behzad Nematollahi * ${ }^{-}$, Ali Nazari, Ming Xia and Jay Sanjayan $\mathbb{}$ \\ Centre for Smart Infrastructure and Digital Construction, Faculty of Science, Engineering and Technology, \\ Swinburne University of Technology, Melbourne, Victoria 3122, Australia; sbong@swin.edu.au (S.H.B.); \\ alinazari@swin.edu.au (A.N.); mxia@swin.edu.au (M.X.); jsanjayan@swin.edu.au (J.S.) \\ * Correspondence: bnematollahi@swin.edu.au
}

Received: 29 August 2019; Accepted: 11 October 2019; Published: 18 October 2019

check for updates

\begin{abstract}
Currently, there are a very limited number of studies on the effect of admixtures on properties of 'one-part' geopolymers. This paper reports the effects of different superplasticizers and retarders on fresh and hardened properties of one-part fly ash-slag blended geopolymers made by different solid activators. Two different grades of sodium silicate, namely anhydrous sodium metasilicate powder $\left(\mathrm{nSiO}_{2} / \mathrm{nNa}_{2} \mathrm{O}=0.9\right)$ and GD Grade sodium silicate powder $\left(\mathrm{nSiO}_{2} / \mathrm{nNa}_{2} \mathrm{O}=2.0\right)$ were used as the solid activators. Five different commercially available superplasticizers, including three modified polycarboxylate-based superplasticizers (denoted as PC1, PC2, and PC3) and two naphthalene-based superplasticizers (denoted as N1 and N2), as well as three different retarders, including sucrose, anhydrous borax and a commercially available retarder, were investigated. Workability, setting time and compressive strength of the mixtures without and with addition of each 'individual' admixture were measured. The results showed the effect of admixtures on the properties of the one-part geopolymers significantly depended on the type of solid activator and the type of admixture used. When GD Grade sodium silicate powder was used as the solid activator, all investigated admixtures not only had no positive effect on the workability and setting time, but also significantly reduced the compressive strength of the mixture. However, when anhydrous sodium metasilicate powder was used as the solid activator, the PC1 and sucrose were the best performing superplasticizer and retarder, respectively, causing no reduction in the compressive strength, but significant increase in the workability (up to $+72 \%$ ) and setting time (up to $+111 \%$ ), respectively as compared to the mixture with no admixture. In addition, the results also showed that addition of 'combined' admixtures (i.e., PC1 in the presence of sucrose) significantly increased the workability (up to $+39 \%$ ) and setting time (up to $+141 \%$ ), but slightly reduced the compressive strength $(-16 \%$ ) of the mixture activated by anhydrous sodium metasilicate powder, as compared to the mixture with no admixture.
\end{abstract}

Keywords: retarder; superplasticizer; one-part geopolymer; just-add-water; setting time; workability; compressive strength

\section{Introduction}

Ordinary Portland cement (OPC) has been widely used as the main binder for production of concrete in the construction industry. However, the manufacture of OPC contributes approximately $5-7 \%$ of the total global $\mathrm{CO}_{2}$ emissions [1]. Moreover, the production of OPC is an energy-intensive activity; 3-7 GJ of energy is needed to manufacture one ton of OPC [2]. Hence, it is essential to develop alternative OPC-less binders for concrete production. Geopolymer is an alternative binder to OPC, which can be manufactured from materials of geological origin (such as metakaolin) or industrial 
by-products (such as fly ash and slag that contain a considerable amount of silica and alumina) with high alkaline activators [3]. The utilization of industrial by-products such as fly ash as the source material in geopolymer production is particularly beneficial as disposition of these industrial by-products occupies large areas in landfills, which could be used for other purposes [4]. According to previous studies, using fly ash as the source material for production of geopolymer consumes up to $60 \%$ less energy and emits up to $80 \%$ less carbon dioxide as compared to production of OPC $[5,6]$. It is worth noting that the environmental footprint of geopolymer considerably depends on the source material and the activator used for its production. Besides the environmental advantages, geopolymers can exhibit a variety of properties and characteristics which are desirable in the construction industry, including high compressive strength, good chemical resistance, adjustable setting time, low shrinkage and excellent fire resistance [7-11].

Although geopolymer can offer the above-mentioned remarkable properties; however, the use of geopolymer, as compared to OPC, has so far been limited to small-scale projects and niche applications. This is mainly attributed to two important obstacles. The first obstacle is the use of user-hostile alkaline solutions to make geopolymers. Conventional geopolymer is synthesized from a 'two-part' mix formulation, which consists of liquid activators and solid aluminosilicate source materials. One of the important drawbacks of the 'two-part' mix formulation is that handling of large amount of corrosive and often viscous alkaline solutions is often difficult and challenging in commercial and large-scale applications of geopolymers [3]. The second obstacle is that geopolymers, especially low-calcium (Class F) fly ash-based mixtures, often require to be cured at elevated temperature to obtain better microstructural development and mechanical properties [12-14]. The necessity for the heat curing does not only limit its in-situ and large-scale applications, but also requires extra cost and energy associated with it, which limits commercial viability of geopolymer.

Several researchers have attempted to tackle both of the aforementioned obstacles by developing ambient temperature cured 'one-part' fly ash-slag blended geopolymers [3,9,15-21]. Such geopolymers are synthesized from a 'just-add-water' mix formulation, where only water is added to a pre-mixed dry material. In the pre-mixed dry material, a small amount of solid activator is used instead of large quantities of alkaline solution, and some percentages of fly ash are replaced with slag. However, the resulting geopolymer concrete often exhibit poor workability and short setting time [9,22], which may limit its commercial viability and large-scale applications. Therefore, it is essential to increase workability and setting time of ambient temperature cured 'one-part' fly ash-slag blended geopolymer concretes to enhance their commercial viability and large-scale applications.

High range water reducers, also known as superplasticizers (SPs), are often added to OPC-based concrete to improve its rheology, workability and mechanical properties [23-25]. It is a common practice to use SPs to improve the workability of OPC-based concrete with lower water content and achieve higher strength and durability. There are several types of SPs commercially available, including lignosulphonates, naphthalene-based, melamine-based, and modified polycarboxylates [25]. In the last few decades, the effect and mechanism of SPs in OPC have been widely studied by many researchers [26-31]. Although SPs were developed and optimized to work in OPC-based mixtures, several studies have investigated the efficiency of SPs in conventional 'two-part' geopolymer-based mixtures. It was found that SPs in general performed poorly in geopolymer systems due to instability of SP under highly alkaline environment [24,25,32-35]. However, studies on the effect of commercial SPs on properties of 'one-part' geopolymers are very limited. For instance, Luukkonen et al. [36] recently investigated the effect of different SPs on properties of a one-part geopolymer mortar made of slag as the source material, in conjunction of microsilica as an additional silica source, and sodium hydroxide powder as the solid activator. The authors concluded that for the investigated one-part geopolymer formulation lignosulfonate, melamine, and naphthalene-based SPs were more effective than polyacrylate and polycarboxylate-based SPs. Alrefaei et al. [37] investigated the effect of different SPs in a one-part geopolymer made of fly ash $(50 \% w / w)$ and slag $(50 \% w / w)$ as the source material and sodium silicate powder $(8 \% w / w)$ as the solid activator with different water contents. They found that 
polycarboxylate-based SP was more effective for mixtures with high water content (i.e., water/precursor $\geq 0.36$ ), while naphthalene-based SP was more effective for mixtures with low water content (i.e., water/precursor $\leq 0.36$ ).

Retarders (RTs) are often added to OPC-based concrete to increase its setting time [38-43]. Similar to SPs, RTs were also developed to work in OPC-based system. Previous studies have investigated the efficiency of RTs in conventional 'two-part' geopolymer mixtures. For instance, Kusbiantoro et al. [44] studied the effect of sucrose and citric acid on fly ash-based geopolymers. They reported that sucrose had retarding effect, while citric acid exhibited accelerating effect. In addition, they also reported that the compressive strength of geopolymer decreased by increasing dosage of sucrose and citric acid. Liu et al. [45] investigated the influence of anhydrous borax on the setting mechanism of fly ash-based geopolymer at elevated temperature. They concluded that anhydrous borax only exhibited the retarding effect when its dosage reached to a certain value. In addition, they also found that the compressive strength of specimens with anhydrous borax was significantly decreased. Garg and White [46] reported that zinc oxide was very effective in retarding the slag-based geopolymer. Other materials such as sodium phosphate [47], phosphoric acid [48], sodium chloride and malic acid [49] were also studied by other researchers as RTs for geopolymers. However, studies on the effect of retarders on properties of one-part geopolymers are very limited. Recently, Oderji et al. [50] investigated the effect of different RTs on a one-part geopolymer composed of fly ash $(85 \% w / w)$, slag $(15 \% w / w)$, and sodium silicate powder $(12 \% w / w)$. Among the admixtures investigated in their study, it was reported that borax was the most effective one when both compressive strength and workability of the mixture was concerned.

Based on the above review, further research on effect of SPs and RTs on properties of one-part geopolymers is necessary. This is because the available results are not yet conclusive about the influences of type and dosage of admixtures used, as well as type of solid activators and source materials, along with time and temperature of curing used for production of one-part geopolymers. Therefore, this study aims to investigate the influence of different commercially available SPs and RTs on both fresh and hardened properties of one-part geopolymer pastes made of fly ash and slag as the source materials and two different grades of sodium silicate powders with different alkali modulus as the solid activators. In addition, it is a common practice to use more than one type of admixture (e.g., a RT in the presence of a SP) to obtain desirable rheological properties of OPC-based concrete. However, the effect of combined admixtures on one-part geopolymers has rarely been studied. Therefore, this study also investigates the effects of 'combined' admixtures (i.e., addition of the best performing SP in the presence of the best performing RT) on properties of the 'one-part' fly ash-slag blended geopolymers.

\section{Materials and Methods}

\subsection{Geopolymer Precursors}

A low-calcium (Class F) fly ash and ground granulated blast furnace slag were used as the aluminosilicate source materials in this study. The fly ash was supplied by Cement Australia Pty Ltd., Brisbane, Australia. The slag was supplied by Building Products Supplies Pty Ltd., Melbourne, Australia. SPECTRO XEPOS X-ray Fluorescence (XRF) spectrometer (SPECTRO Analytical Instruments Inc., Mahwah, NJ, USA) was used to determine the chemical composition of the fly ash and slag used in this study. Table 1 presents the results of XRF analysis. 
Table 1. Chemical composition of the slag and fly ash (wt \%).

\begin{tabular}{ccc}
\hline \multirow{2}{*}{ Chemical } & \multicolumn{2}{c}{ Component } \\
\cline { 2 - 3 } & Slag & Fly Ash \\
\hline $\mathrm{SiO}_{2}$ & 32.76 & 51.52 \\
$\mathrm{Al}_{2} \mathrm{O}_{3}$ & 12.37 & 27.83 \\
$\mathrm{Fe}_{2} \mathrm{O}_{3}$ & 0.54 & 11.77 \\
$\mathrm{CaO}$ & 44.56 & 2.20 \\
$\mathrm{MgO}$ & 5.15 & 1.30 \\
$\mathrm{~K}_{2} \mathrm{O}$ & 0.33 & 0.60 \\
$\mathrm{Na}_{2} \mathrm{O}$ & 0.22 & 0.40 \\
$\mathrm{MnO}_{\mathrm{TiO}}$ & 0.15 & 0.15 \\
$\mathrm{P}_{2} \mathrm{O}_{5}$ & 0.51 & 1.50 \\
$\mathrm{SO}_{3}$ & 0.88 & 0.73 \\
L.O.I. $^{1}$ & 4.26 & 0.20 \\
& 0.09 & 1.80 \\
\hline
\end{tabular}

\subsection{Solid Activators}

Two types of sodium silicate powders, namely anhydrous sodium metasilicate and GD Grade sodium silicate were used as the solid activators in this study. The anhydrous sodium metasilicate and GD Grade sodium silicate powders were supplied by Redox Pty Ltd., Melbourne, Australia and PQ Australia Pty Ltd., Melbourne, Australia, respectively. The specifications of different types of sodium silicate powders are presented in Table 2.

Table 2. Specifications of different types of sodium silicate powders.

\begin{tabular}{ccccc}
\hline Type of Activator & $\mathbf{n S i O}_{\mathbf{2}} / \mathbf{n N a}_{\mathbf{2}} \mathbf{O}$ & $\mathbf{S i O}_{\mathbf{2}}{ }^{\mathbf{a}} \mathbf{( F R \% )}$ & $\left.\mathbf{N a}_{\mathbf{2}} \mathbf{O}^{\mathbf{a}} \mathbf{( w t} \%\right)$ & $\mathbf{H}_{\mathbf{2}} \mathbf{O}(\mathbf{w t} \%)$ \\
\hline Anhydrous sodium metasilicate & 0.9 & 46 & 51 & $3^{\mathrm{b}}$ \\
GD Grade sodium silicate & 2.0 & 54 & 27 & $18^{\mathrm{b}}$ \\
\hline
\end{tabular}

\footnotetext{
${ }^{a}$ Average $w t^{\circ} \%$ reported by the supplier; ${ }^{b}$ Chemically bound water in the powder which is released when dissolved
} in water.

\subsection{Admixtures}

Five different SPs including three modified polycarboxylate (denoted as PC1, PC2 and PC3) and two naphthalene-based SPs (denoted as N1 and N2) were investigated in this study. These SPs are commercially available products in Australia supplied by BASF (Melbourne) and SIKA (Melbourne). The specifications of the SPs investigated in this paper are presented in Table 3.

Table 3. Chemical and physical properties of superplasticizers.

\begin{tabular}{|c|c|c|c|c|c|}
\hline SP ID & Commercial Name & Chemical Base & Color & $\mathrm{pH}$ & Density $\left(\mathrm{g} / \mathrm{cm}^{3}\right)$ \\
\hline PC1 & MasterGlenium SKY 8379 & Modified polycarboxylate & Brown & 5.9 & 1.06 \\
\hline PC2 & ViscoCrete PC HRF-1 & Modified polycarboxylate & Light brown & n.r. ${ }^{1}$ & n.r. ${ }^{1}$ \\
\hline PC3 & ViscoCrete 5-500 & Modified polycarboxylate & Clear brown & $5.0 \pm 1.0$ & 1.07 \\
\hline N1 & MasterRheobuild 1000NT & $\begin{array}{l}\text { Sodium naphthalene } \\
\text { formaldehyte sulphonate }\end{array}$ & Dark brown & 7.0 & 1.20 \\
\hline N2 & Sikament NN & $\begin{array}{l}\text { Sodium naphthalene } \\
\text { formaldehyte sulphonate }\end{array}$ & Brown & 7. $0 \pm 0.5$ & 1.20 \\
\hline
\end{tabular}

Note: The $\mathrm{pH}$ and density values are reported by the suppliers at $20^{\circ} \mathrm{C} ;{ }^{1}$ not reported by the supplier.

Three types of RTs were used in this paper. Two of them were the proposed RTs for geopolymer-based systems including sucrose and anhydrous borax (henceforth referred to as borax) powders. The sucrose (denoted as S) and borax (denoted as B) were supplied by Chem-Supply Pty Ltd., Adelaide, Australia and IMCD Australia Limited, Melbourne, Australia, respectively. A commercially 
available retarder for OPC concrete (denoted as RT) supplied by BASF, Melbourne, Australia was also investigated in this paper. The specifications of the RTs investigated in this paper are presented in Table 4.

Table 4. Physical properties of retarders (RTs).

\begin{tabular}{|c|c|c|c|c|}
\hline RT ID & Commercial Name & Physical Form & Color & Density $\left(\mathrm{g} / \mathrm{cm}^{3}\right)$ \\
\hline$S$ & Sucrose RA & Powder & White & 1.59 \\
\hline B & Borax Anhydrous Pyrobor & Powder & White & 1.12 \\
\hline RT & MasterSet RT 122 & Liquid & Dark brown & 1.05 \\
\hline
\end{tabular}

Note: The density values are reported by the suppliers at $20^{\circ} \mathrm{C}$.

\section{Experimental Procedures}

The experimental program performed was divided into two parts (Part I and Part II). In Part I, different SPs and RTs were used separately to study the effects of addition of an individual admixture (i.e., a SP or a $R T$ ) on properties of one-part fly ash-slag blended geopolymer made by different activators. The best performing SP and RT exhibiting desirable properties were selected based on the results obtained in Part I. In Part II, the best performing SP and RT were used together to study the effects of addition of combined admixtures (i.e., the best performing SP in the presence of the best performing $R T$ ) on properties of the one-part geopolymer.

\subsection{Mixture Proportions}

In this paper, two series of geopolymer mixtures were prepared based on the type of activator, namely AN series (which use anhydrous sodium metasilicate powder as the activator) and GD series (which use GD Grade sodium silicate powder as the activator). Each series comprised of nine mixtures as shown in Table 5. In all mixtures, the mass ratio of fly ash to slag was kept constant equal to 1.0. The mass ratio of solid activator to geopolymer precursors (fly ash + slag) was also kept constant equal to 0.1 . The water-to-geopolymer-solids ratio (W/GP-solids) of each mixture as defined by Hardjito et al. [51] was also kept constant equal to 0.367 . The mass ratio of water to geopolymer precursors (fly ash + slag) in AN series mixtures was equal to 0.4. In order to keep the W/GP-solids constant in all mixtures, the mass ratio of water to geopolymer precursors in GD series mixtures was adjusted (equal to 0.379 ) to correspond to the same W/GP-solids of 0.367 . The mass ratio of SPs or RTs to geopolymer precursors in each mixture was kept constant equal to 0.01 .

Table 5. The mixture proportions of one-part fly ash-slag blended geopolymer paste.

\begin{tabular}{ccccccc}
\hline Mix ID & Geopolymer Precursors & Solid Activator & Water & Superplasticizer & Retarder & W/GP-Solids \\
\hline AN & 1.000 & $0.100^{\mathrm{a}}$ & 0.400 & - & - & 0.367 \\
AN-PC1 & 1.000 & $0.100^{\mathrm{a}}$ & 0.400 & $0.010^{\mathrm{c}}$ & - & 0.367 \\
AN-PC2 & 1.000 & $0.100^{\mathrm{a}}$ & 0.400 & $0.010^{\mathrm{d}}$ & - & 0.367 \\
AN-PC3 & 1.000 & $0.100^{\mathrm{a}}$ & 0.400 & $0.010^{\mathrm{e}}$ & - & 0.367 \\
AN-N1 & 1.000 & $0.100^{\mathrm{a}}$ & 0.400 & $0.010^{\mathrm{f}}$ & - & 0.367 \\
AN-N2 & 1.000 & $0.100^{\mathrm{a}}$ & 0.400 & $0.010^{\mathrm{g}}$ & - & 0.367 \\
AN-S & 1.000 & $0.100^{\mathrm{a}}$ & 0.400 & - & $0.010^{\mathrm{h}}$ & 0.367 \\
AN-B & 1.000 & $0.100^{\mathrm{a}}$ & 0.400 & - & $0.010^{\mathrm{i}}$ & 0.367 \\
AN-RT & 1.000 & $0.100^{\mathrm{a}}$ & 0.400 & - & $0.010^{\mathrm{j}}$ & 0.367 \\
GD & 1.000 & $0.100^{\mathrm{b}}$ & 0.379 & - & - & 0.367 \\
GD-PC1 & 1.000 & $0.100^{\mathrm{b}}$ & 0.379 & $0.010^{\mathrm{c}}$ & - & 0.367 \\
GD-PC2 & 1.000 & $0.100^{\mathrm{b}}$ & 0.379 & $0.010^{\mathrm{d}}$ & - & 0.367 \\
GD-PC3 & 1.000 & $0.100^{\mathrm{b}}$ & 0.379 & $0.010^{\mathrm{e}}$ & - & 0.367 \\
GD-N1 & 1.000 & $0.100^{\mathrm{b}}$ & 0.379 & $0.010^{\mathrm{f}}$ & - & 0.367 \\
GD-N2 & 1.000 & $0.100^{\mathrm{b}}$ & 0.379 & $0.010^{\mathrm{g}}$ & - & 0.367 \\
GD-S & 1.000 & $0.100^{\mathrm{b}}$ & 0.379 & - & - & $0.010^{\mathrm{h}}$ \\
GD-B & 1.000 & $0.100^{\mathrm{b}}$ & 0.379 & - & $0.010^{\mathrm{i}}$ & 0.367 \\
GD-RT & 1.000 & $0.100^{\mathrm{b}}$ & 0.379 & $-010^{\mathrm{j}}$ & 0.367 \\
\hline
\end{tabular}

Note: All numbers are mass ratios of the geopolymer precursors (fly ash + slag) weight; ${ }^{a}$ Anhydrous sodium metasilicate powder; ${ }^{b}$ GD Grade sodium silicate powder; ${ }^{c}$ PC1 superplasticizer; ${ }^{d}$ PC2 superplasticizer; ${ }^{\text {e }}$ PC3 superplasticizer; ${ }^{\mathrm{f}} \mathrm{N} 1$ superplasticizer; ${ }^{\mathrm{g}} \mathrm{N} 2$ superplasticizer; ${ }^{\mathrm{h}}$ Sucrose; ${ }^{i}$ Borax; ${ }^{\mathrm{j}}$ RT retarder. 


\subsection{Mixing, Casting, Curing and Testing of Specimens}

To prepare the mixtures, fly ash, slag, solid activator and retarder (if any) were added to a 20-littre Hobart mixer and dry mixed at low-speed for three min. Tap water was then slowly added to the mixture and the mixture was mixed for another two min at low-speed. Subsequently, the SP (if any) was added to the mixer and the mixture was mixed for another eight min at high-speed. The workability of each mixture was measured immediately after completion of the mixing process by conducting a mini-slump test in accordance with ASTM C1437 [52]. The initial and final setting times of each mixture were measured by using a Vicat apparatus according to AS/NZS 2350.4 [53]. The setting time was measured from the time that the water was added to the dry materials. Six $25 \mathrm{~mm}$ cube specimens were cast from each mixture for compression tests. The specimens were placed in a sealed container and put in an oven at $60^{\circ} \mathrm{C}$ for $24 \mathrm{~h}$. After the end of heat curing period, the specimens were removed from the oven and left in the laboratory environment to cool down and then removed from the molds. After de-molding, the specimens were stored at ambient temperature $\left(23 \pm 3^{\circ} \mathrm{C}\right)$ until the day of testing. Previous studies reported that heat-cured geopolymers typically reach more than $90 \%$ of their long-term strength after three days $[3,17,18]$. Therefore, all specimens were tested three days after casting in this study. According to AS 1012.9 [54], compression tests were conducted under load control at the rate of $20 \pm 2 \mathrm{MPa} / \mathrm{min}$.

\section{Results and Discussions}

\subsection{Effects of Different Superplasticisers}

\subsubsection{Workability}

The average spread diameter of each mixture without and with different SPs is presented in Figure 1. By comparing the mixtures without using any SP, the "AN" mix exhibited larger spread diameters both before and after drop of the flow table as compared to "GD" mix. This is despite the fact that both of these mixtures had identical W/GP-solids, as shown in Table 5. Previous studies reported that slump or slump flow is affected by yield stress of the paste $[55,56]$. Therefore, the higher workability of "AN" paste indicates its lower yield stress than that of "GD" paste.

As can be seen in Figure 1a, the spread diameters of "AN-PC1" and "AN-N2" pastes (both before and after drop of the flow table) were considerably increased with respect to those of the paste without any SP ("AN" paste). As compared to "AN" paste, the increase in spread diameter of "AN-PC1" and "AN-N2" pastes before drop of the flow table were $72 \%$ and $40 \%$, respectively and after drop of the flow table were $40 \%$ and $41 \%$, respectively. Although the average spread diameters of "AN-N1" and "AN" pastes before drop of the flow table were comparable; however, the spread diameter of "AN-N1" paste after drop of the flow table was $24 \%$ larger than that of "AN" paste. On the other hand, the spread diameters of "AN-PC2" and "AN-PC3" pastes before and after drop of the flow table were $4-9 \%$ smaller as compared to those of "AN" paste.

Based on the aforementioned results, it can be concluded that among the SPs investigated in this study, PC1, N2 and N1 were chemically stable (to some extent) in the anhydrous sodium metasilicate solution, thus provided up to $40 \%$ increase in workability of the geopolymer paste [32,57]. However, PC2 and PC3 were chemically unstable (i.e., experienced structural changes) in the anhydrous sodium metasilicate solution, and thereby lost their superplasticizing properties. 
(a)

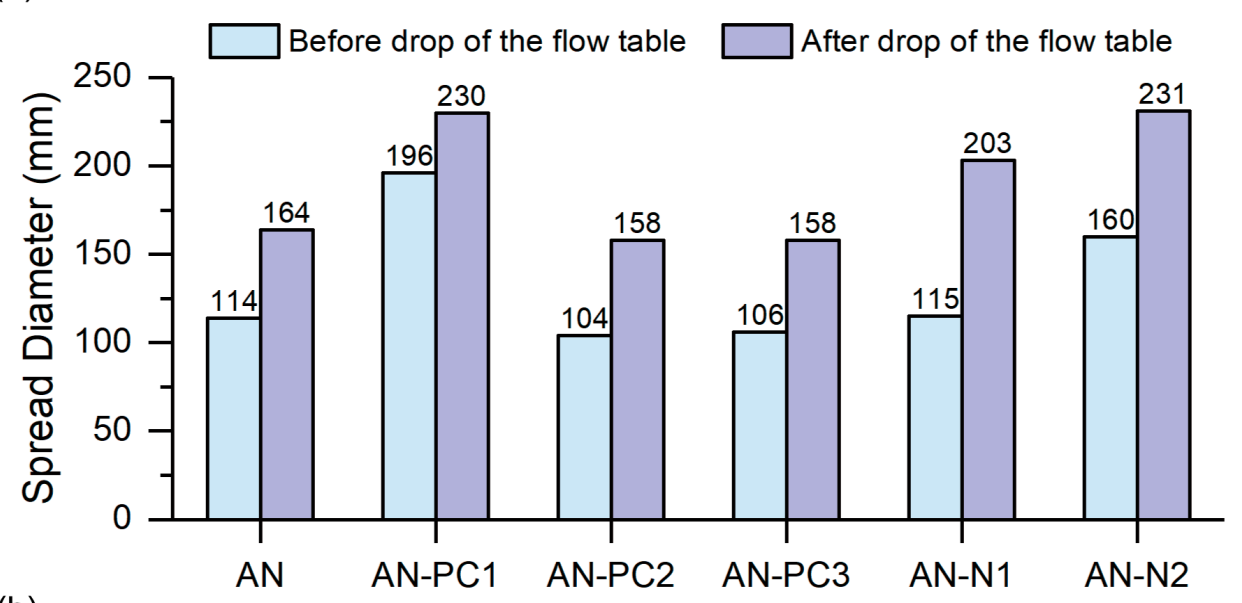

(b)

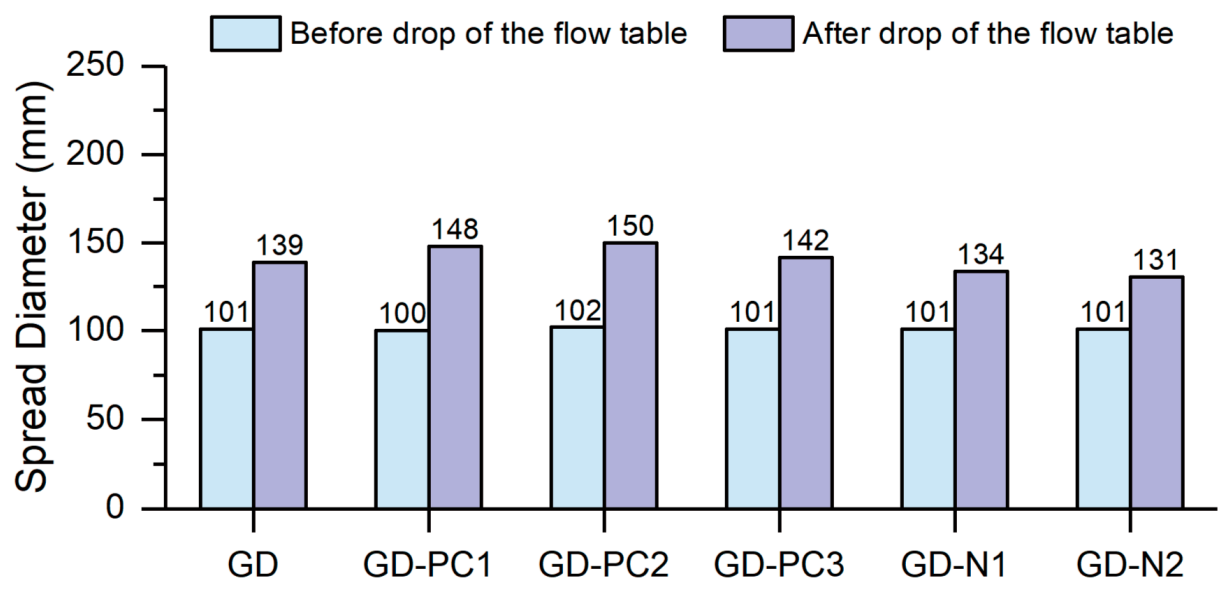

Figure 1. Effect of different SPs on workability of one-part fly ash-slag blended geopolymer pastes activated by (a) Anhydrous sodium metasilicate powder, and (b) GD Grade sodium silicate powder.

It is interesting to note that the PC1 supplied by BASF Australia was effective in increasing the workability of the geopolymer paste, but PC2 and PC3 supplied by SIKA Australia were not effective. Considering that all these SPs (PC1, PC2 and PC3) were PCE-based, therefore it can be said that not all types of PCE-based SPs undergo structural changes in the anhydrous sodium metasilicate solution. Palacios and Puertas $[32,57]$ also stated that not all types of SPs undergo structural changes in highly alkaline media and the structural degradation depends on the type of SP and the type of alkaline solution used. However, due to unavailability of technical data (such as molecular weight, chemical structure, additives, etc.) for these commercial superplasticisers, it is not possible to investigate the cause of stability of PC1 versus instability of PC2 and PC3 in the anhydrous sodium metasilicate solution.

On the contrary, as can be seen in Figure 1b, in case of the mixtures activated with GD Grade sodium silicate powder, the average spread diameter of all pastes with and without SP before drop of the flow table was almost $100 \mathrm{~mm}$, which is equal to the bottom diameter of the mini-slump cone used in this paper. After drop of the flow table, the average spread diameter of all pastes with different SPs had no significant increase or decrease with respect to that of the paste without SP. Therefore, it can be concluded that all SPs investigated in this paper had no significant effect on the workability of the mixture activated by GD Grade sodium silicate powder. This is most likely because all SPs studied in this paper experienced structural changes resulting in loss of their superplasticizing properties when GD Grade sodium silicate powder was used as the activator $[32,57]$. 


\subsubsection{Compressive Strength}

Figure 2 presents the compressive strength of each mixture without and with different SPs. By comparing the pastes without any SP, it was found that the compressive strength of "GD" paste was $16 \%$ higher than that of "AN" paste. This is due to the higher modulus of GD Grade sodium silicate $\left(\mathrm{nSiO}_{2} / \mathrm{nNa}_{2} \mathrm{O}=2.0\right)$ as compared to that of anhydrous sodium metasilicate $\left(\mathrm{nSiO}_{2} / \mathrm{nNa}_{2} \mathrm{O}=\right.$ 0.9). Previous studies showed that activator with higher modulus provided more soluble silicate into the geopolymeric system, which promoted the geopolymerisation reaction and resulted in increasing the strength $[58,59]$.

(a)

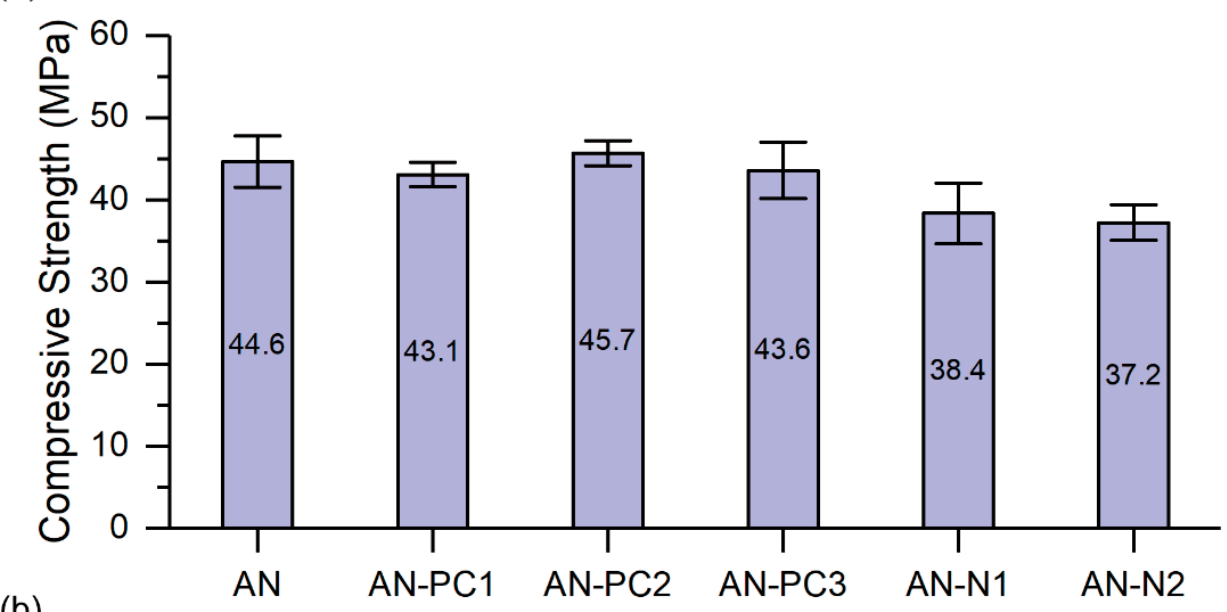

(b)

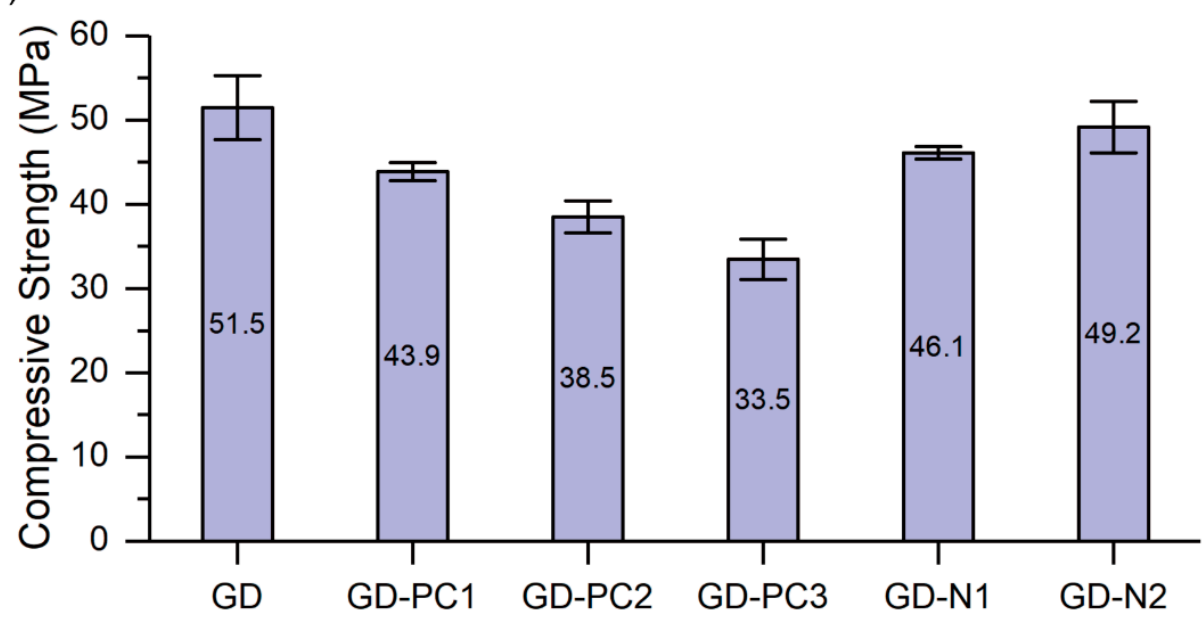

Figure 2. Effect of different SPs on compressive strength of one-part fly ash-slag blended geopolymer pastes activated by (a) Anhydrous sodium metasilicate powder, and (b) GD Grade sodium silicate powder.

According to Figure 2a, the addition of the PC-based SPs (i.e., PC1, PC2 and PC3) to the one-part geopolymer paste activated by anhydrous sodium metasilicate powder did not have any significant effect on the compressive strength of the paste with reference to the paste without any SP. However, the compressive strengths of the pastes with the N-based SPs (i.e., N1 and N2) were decreased as compared to the paste without any SP. The decrease in compressive strength of "AN-N1" and "AN-N2" pastes was $14 \%$ and $17 \%$, respectively with reference to "AN" paste. On the contrary, for the mixtures activated with GD Grade sodium silicate (Figure $2 b$ ), the compressive strength of the pastes with the PC-based SPs was remarkably reduced with respect to that of the paste without SP. The reduction in the compressive strengths of "GD-PC1", "GD-PC2" and "GD-PC3" pastes were 15\%, 25\% and 35\%, respectively with reference to "GD" paste. As can be seen in Figure $2 b$, the decrease in the compressive 
strength of the pastes with the N-based SPs was less significant as compared to that of the pastes with PC-based SPs. These results suggested that the variations of compressive strengths obtained in this paper are closely related to the chemical stability of SPs in different alkaline solutions [25,32]. Based on Figures 1 and 2, it can be concluded that PC1 and anhydrous metasilicate powder exhibited good compatibility as the workability of the resultant geopolymer paste was significantly increased, and at the same time no strength reduction was observed.

\subsection{Effects of Different Retarders}

\subsubsection{Setting Time}

Table 6 presents the initial and final setting times of each mixture without and with different RTs. It should be noted that the setting time measurement was ended if the initial setting time of the paste was beyond $360 \mathrm{~min}$, which is more than enough for all construction applications. As can be seen in this table, the initial and final setting times of "AN" paste were 169 min and $255 \mathrm{~min}$, respectively, while the initial setting time of "GD" paste was beyond $360 \mathrm{~min}$. The anhydrous sodium metasilicate solution has higher $\mathrm{pH}$ value $\left(\mathrm{pH}=13.65\right.$ at $\left.20^{\circ} \mathrm{C}\right)$ than that of the GD Grade sodium silicate solution ( $\mathrm{pH}=12.71$ at $20^{\circ} \mathrm{C}$ ). The dissolution rate of amorphous aluminosilicates is higher at high $\mathrm{pH}$ environment $(\mathrm{pH}>13)$ which accelerates the geopolymerisation reaction and results in shorter setting time $[11,60]$. Thus, "AN" paste has shorter setting time than that of "GD" paste due to its faster geopolymerisation reaction.

Table 6. Effect of different RTs on setting time of one-part fly ash-slag blended geopolymer pastes activated by different activators.

\begin{tabular}{ccc}
\hline \multirow{2}{*}{ Mix ID } & \multicolumn{2}{c}{ Setting Time (min) } \\
\cline { 2 - 3 } & Initial & Final \\
\hline AN & 169 & 255 \\
AN-S & 357 & 495 \\
AN-B & 342 & 466 \\
AN-RT & 359 & 457 \\
GD & $>360$ & $-{ }^{*}$ \\
GD-S & $>360$ & $-{ }^{*}$ \\
GD-B & $>360$ & $-{ }^{*}$ \\
GD-RT & $>360$ & $-{ }^{*}$.
\end{tabular}

As can be seen in Table 6, for the pastes activated with anhydrous sodium metasilicate, all RTs studied in this paper significantly increased the initial and final setting times in the range of $102-112 \%$ and $79-94 \%$, respectively with respect to the paste without retarder ("AN" paste). Among the RTs investigated in this study, sucrose was the most effective retarder to prolong the setting time. Kusbiantoro et al. [44] also reported the retarding effect of sucrose on 'two-part' fly ash-based geopolymer. They envisaged that the $\mathrm{HO}-\mathrm{C}-\mathrm{C}=\mathrm{O}$ groups from sucrose were transformed into acid complexes under alkaline environment, which can chelate the calcium, silicon and aluminum ions in the system and delay the formation of calcium silicate hydrates (C-S-H) and calcium aluminate silicate hydrate (C-A-S-H) gels [61]. These gels can be found on the geopolymers containing slag [62-66]. According to Table 6, the initial and final setting times of the paste with borax ("AN-B") were 15 min and $29 \mathrm{~min}$, respectively shorter than those of the paste with sucrose. The retarding mechanism of borax was studied in detail by Liu et al. [45]. Although the commercial retarder significantly increased the initial and final setting times of the paste as compared to that of the paste without retarder, the final setting time of the paste with the commercial retarder was still $38 \mathrm{~min}$ shorter than of the paste with sucrose. 
According to Table 6, the initial setting time of all pastes (with and without retarder) activated by GD Grade sodium silicate was more than $360 \mathrm{~min}$, which is acceptable for all construction applications. The final setting time of these pastes was not measured since their initial setting time was beyond $360 \mathrm{~min}$.

\subsubsection{Workability}

Figure 3 presents the average spread diameter of each mixture without and with different RTs. For the pastes activated by anhydrous sodium metasilicate (Figure 3a), all RTs investigated in this paper improved the spread diameter of the pastes of up to $27 \%$ after drop of the flow table. According to Ramachandran [61], most RTs and water reducers are based on the same source materials, two of which are sucrose and borates. Thus, the workability (spread diameter) of the pastes was improved as they can act like plasticizers in this case. Also, in the case of "AN-RT" paste, the additional water from this commercial retarder may also contribute to improving the workability of the paste since this retarder was in liquid form.

(a)

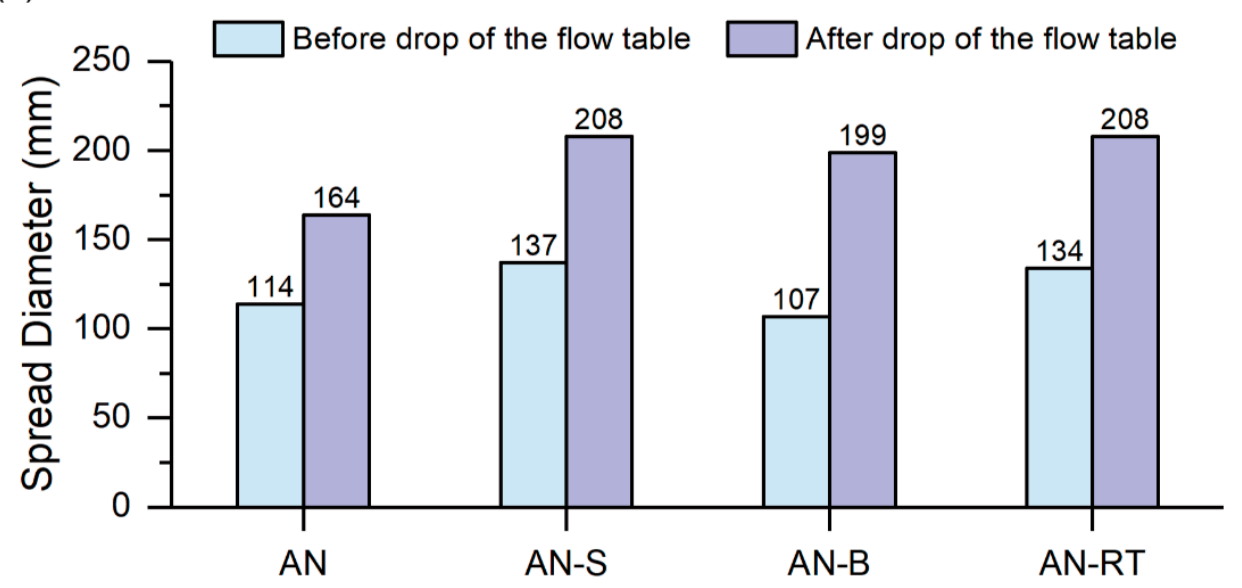

(b)

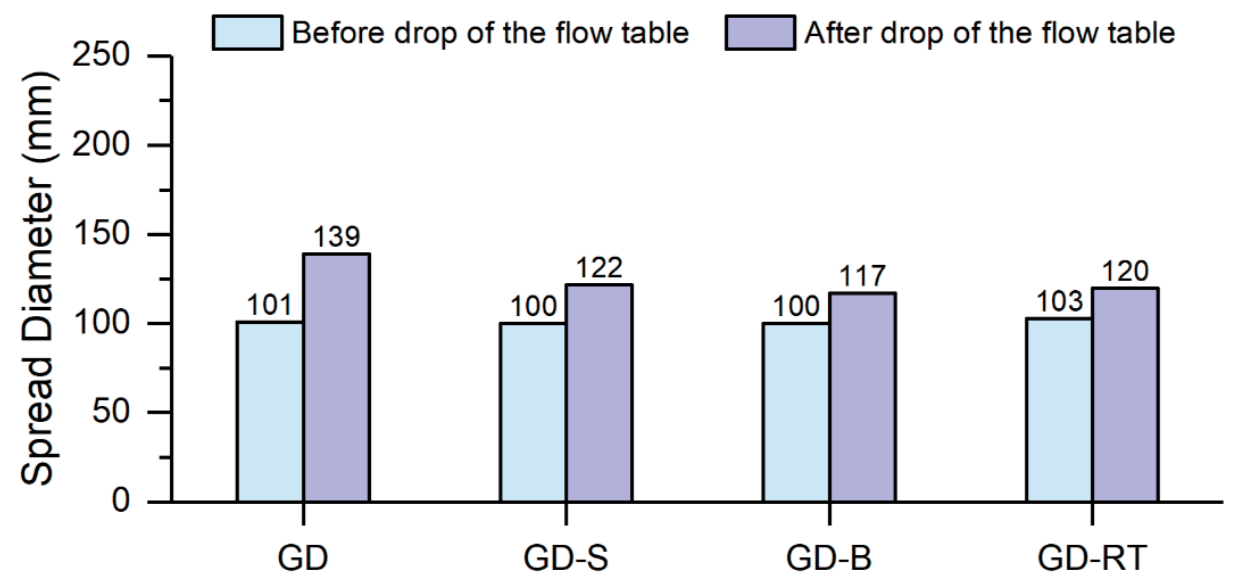

Figure 3. Effect of different RTs on workability of one-part fly ash-slag blended geopolymer pastes activated by (a) Anhydrous sodium metasilicate powder, and (b) GD Grade sodium silicate powder.

On the other hand, in the case of the mixtures activated by GD Grade sodium silicate (Figure 3b), the average spread diameter of the pastes containing RTs before drop of the flow table was comparable to that of the paste without retarder (equal to $100 \mathrm{~mm}$ ). However, after drop of the flow table the average spread diameter of the pastes with different RTs was 12-16\% smaller with respect to that of the paste without retarder. These results indicated that the additional fluidifying effect from the RTs studied in this paper greatly depends on the type of solid activator used. Therefore, it can be said that 
all types of RTs studied in this paper had negative effect on the workability of the pastes activated by GD Grade sodium silicate. However, an opposite trend was observed for the pastes activated by anhydrous sodium metasilicate.

\subsubsection{Compressive Strength}

Figure 4 presents the compressive strength of each mixture without and with different RTs. In case of the pastes activated by anhydrous sodium metasilicate (Figure 4a), all RTs had no effect on the compressive strength except the commercial retarder. The compressive strength of the paste with the commercial retarder was $10 \%$ lower than that of the paste without retarder. However, as can be seen in Figure $4 b$, all RTs reduced the compressive strength of the pastes activated by GD Grade sodium silicate. The decrease in the compressive strength of the pastes with sucrose, borax and the commercial retarder was $37 \%, 46 \%$ and $14 \%$, respectively with reference to the paste without retarder. Previous studies also reported a decrease in compressive strength of "two-part" geopolymer when sucrose or borax was used as the retarder $[44,45,67]$.

(a)

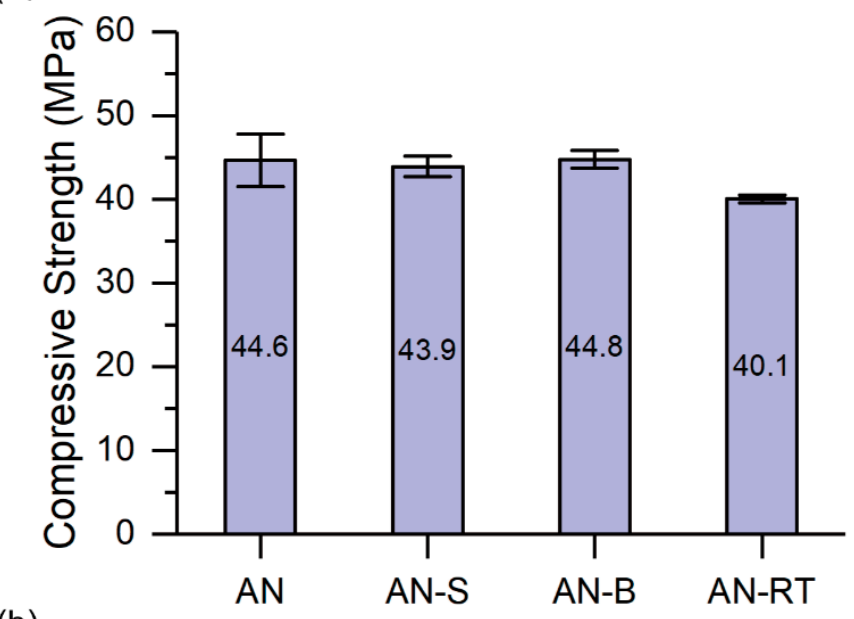

(b)

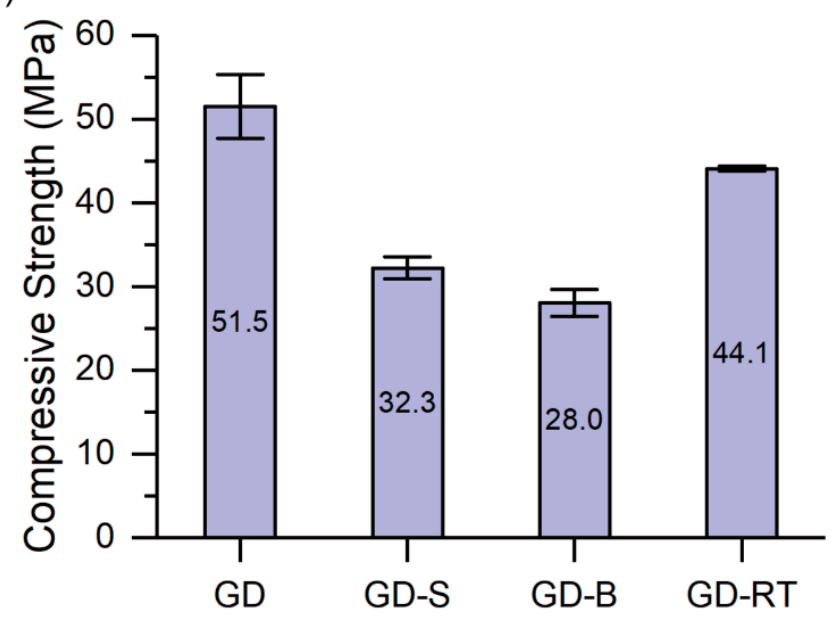

Figure 4. Effect of different RTs on compressive strength of one-part fly ash-slag blended geopolymer pastes activated by (a) Anhydrous sodium metasilicate powder, and (b) GD Grade sodium silicate powder.

Based on the results obtained in this paper, the compatibility between activator and retarder has a significant influence on the fresh properties and strength of "one-part" fly ash-slag blended geopolymer paste. As discussed in Sections 4.2.1-4.2.3, when anhydrous sodium metasilicate was used as the activator, all RTs studied in this paper exhibited positive effect on the workability and setting 
time of the one-part fly ash-slag blended geopolymer mixtures, without decreasing the compressive strength. In addition, sucrose was the most effective retarder among the RTs studied in this paper. However, when GD Grade sodium silicate was used as the activator an opposite trend (i.e., reduction in workability and compressive strength) was observed.

\subsection{Effects of Combined Admixtures}

Based on the results presented in Sections 4.1 and 4.2, PC1, sucrose and borax were selected to investigate the effect of combined SP and retarder on the one-part fly ash-slag blended geopolymer paste activated by anhydrous sodium metasilicate. Table 7 presents the workability, setting time and compressive strength of the pastes with and without the 'combined admixtures'. As shown in this table, the average spread diameter of the pastes with the combined admixtures was larger (both before and after drop of the flow table) than that of the paste without any admixture. However, comparison of the workability of the pastes with the combined admixtures ("AN-PC1-S" and "AN-PC1-B") versus the paste with only the PC1 ("AN-PC1") showed that the workability of "AN-PC1-S" and "AN-PC1-B" pastes were lower than that of "AN-PC1" paste. This may be due to the competitive absorption between the PC1 and sucrose or borax. It was envisaged that the absorption of the PC1 was reduced due to the presence of sucrose or borax and resulted in reduction in fluidity of the paste. Several authors had reported similar competitive absorption between SP and RT in OPC and sulphoaluminate cement [68-71].

Table 7. Effect of combined admixtures on one-part fly ash-slag blended geopolymer paste.

\begin{tabular}{|c|c|c|c|c|c|}
\hline \multirow[b]{2}{*}{ Mix ID } & \multirow{2}{*}{$\begin{array}{l}\text { Compressive } \\
\text { Strength (MPa) }\end{array}$} & \multicolumn{2}{|c|}{ Workability } & \multicolumn{2}{|c|}{ Setting Time } \\
\hline & & $\begin{array}{l}\text { Before Drop of } \\
\text { Flow Table (mm) }\end{array}$ & $\begin{array}{c}\text { After Drop of } \\
\text { Flow Table (mm) }\end{array}$ & $\begin{array}{c}\text { Initial } \\
(\mathrm{min})\end{array}$ & $\begin{array}{l}\text { Final } \\
\text { (min) }\end{array}$ \\
\hline $\mathrm{AN}$ & $44.6 \pm 3.1$ & 114 & 164 & 169 & 255 \\
\hline AN-PC1-S ${ }^{a}$ & $37.5 \pm 2.8$ & 159 & 205 & 407 & 497 \\
\hline AN-PC1-B ${ }^{b}$ & $32.8 \pm 3.7$ & 133 & 206 & 404 & 484 \\
\hline
\end{tabular}

The setting time of the pastes with the 'combined admixtures' was significantly extended compared to the paste without any admixture. The initial and final setting times of "AN-PC1-S" and "AN-PC1-B" pastes were $139-141 \%$ and $90-95 \%$, respectively longer with respect to "AN" paste. By comparing these results with that of the pastes with only the retarder ("AN-S" and "AN-B"), the initial setting time of the pastes with the combined admixtures was $14-18 \%$ longer than that of the pastes with only the retarder. This may be due to the fluidifying effect of PC1 and/or extra water content from PC1 that prolonged the setting time of the pastes.

As shown in Table 7, the compressive strength of the pastes with the 'combined admixtures' was lower than that of the paste without any admixture. The compressive strength of "AN-PC1-S" and "AN-PC1-B" pastes were $16 \%$ and $26 \%$, respectively lower than that of "AN" paste. In addition, the compressive strength of "AN-PC1-S" and "AN-PC1-B" pastes was 15-27\%, respectively lower than that of the pastes with only the RT (Figure 4). Zhang et al. [69] also reported the compressive strength of sulphoaluminate cement with combined admixtures (combination of a SP with a RT) was decreased. It was reported that the reduction of compressive strength was due to the retarding effect of both retarder and SP, causing some cement grains unreacted. Based on the results presented in Table 7 , the combination of PC1 and sucrose would be more effective than the combination with of PC1 and borax as "AN-PC1-S" paste exhibited higher compressive strength, workability and longer setting time as compared to "AN-PC1-B" paste. 


\section{Conclusions}

This study investigated the effects of different SPs and RTs on fresh and hardened properties of the one-part fly ash-slag blended geopolymers activated by two different grades of solid sodium silicate, namely anhydrous sodium metasilicate and GD Grade sodium silicate powders. The results revealed that efficiency of different SPs and RTs on the properties of the one-part geopolymers significantly depended on the type of solid activator, as well as the type SP and RT used. Based on the experimental results obtained in this study, the following specific conclusions can be drawn:

1. For the mixture activated by the anhydrous sodium metasilicate powder (with $\mathrm{nSiO}_{2} / \mathrm{nNa}_{2} \mathrm{O}=$ 0.9), the PC1 (a modified polycarboxylate-based SP) was the most effective SP. The use of PC1 resulted in $72 \%$ and $40 \%$ increase in the average spread diameters of the paste before and after drop of the flow table, respectively, as compared to the paste without using any SP. At the same time, the use of PC1 did not reduce the compressive strength of the paste.

2. For the mixture activated by GD Grade sodium silicate powder (with $\mathrm{nSiO}_{2} / \mathrm{nNa}_{2} \mathrm{O}=2.0$ ), none of the investigated SPs were effective in increasing the workability. In addition, the use of naphthalene-based (N-based) SPs resulted in a marginal (up to 10\%) reduction in the compressive strength, while the use of polycarboxylate-based (PC-based) SPs resulted in a significant (up to $35 \%$ ) reduction in the compressive strength, as compared to the paste without using any SP.

3. All investigated RTs significantly increased the initial setting time (up to $112 \%$ ), final setting time (up to $94 \%$ ) and workability (up to $27 \%$ ) of the paste activated by anhydrous sodium metasilicate powder, with no significant effect on the compressive strength. Among the RTs investigated in this study, sucrose was the most effective one in retarding the setting time, with positive effect on the workability and no reduction of the compressive strength.

4. When GD Grade sodium silicate powder was used as the solid activator, the workability and compressive strength of the paste containing the RTs were up to $16 \%$ and $46 \%$ lower, respectively, as compared to the paste without using any RT.

5. When using the 'combined admixtures' (i.e., PC1 in the presence of either sucrose or borax), PC1 was more compatible with sucrose than borax. In other words, the paste containing both PC1 and sucrose exhibited higher compressive strength and workability, along with longer setting time, as compared to the paste containing both PC1 and borax.

6. The compressive strength of the paste containing the 'combined admixtures' was up to $26 \%$ lower than that of the paste with no admixture. This may be due to the retarding effect of both the retarder and the SP.

7. The workability of the paste containing the 'combined admixtures' was up to $32 \%$ lower than that of the paste containing only PC1. This may be due to competitive absorption between PC1 and sucrose or borax. It was envisaged that the absorption of PC1 was reduced due to the presence of sucrose or borax and resulted in the in the fluidity reduction of the paste.

8. The initial setting time of the paste containing the 'combined admixtures' was up to $18 \%$ longer than that of the paste containing only the retarder (either sucrose or borax). This may be due to the fluidifying effect of PC1 and/or extra water content from PC1 that prolonged the setting time.

Author Contributions: Conceptualization, B.N.; Data curation, S.H.B.; Formal analysis, S.H.B. and M.X.; Investigation, S.H.B. and M.X.; Methodology, B.N. and M.X.; Project administration, A.N. and J.S.; Resources, A.N.; Supervision, B.N., A.N. and J.S.; Writing—original draft, S.H.B.; Writing—review \& editing, B.N. and J.S.

Funding: This research was funded by the Australian Research Council Discovery Grant DP170103521, Linkage Infrastructure Grant LE170100168, and Discovery Early Career Researcher Grant DE180101587.

Acknowledgments: The authors would also like to thank the technical staff at Smart Structures Laboratory, Swinburne University of Technology for their assistance during the experimental work.

Conflicts of Interest: The authors declare no conflict of interest. 


\section{References}

1. Huntzinger, D.N.; Eatmon, T.D. A life-cycle assessment of Portland cement manufacturing: Comparing the traditional process with alternative technologies. J. Clean. Prod. 2009, 17, 668-675. [CrossRef]

2. Taylor, M.; Tam, C.; Gielen, D. Energy efficiency and $\mathrm{CO}_{2}$ emissions from the global cement industry. Korea 2006, 50, 61-67.

3. Nematollahi, B.; Sanjayan, J.; Shaikh, F.U.A. Synthesis of heat and ambient cured one-part geopolymer mixes with different grades of sodium silicate. Ceram. Int. 2015, 41, 5696-5704. [CrossRef]

4. Sarker, P.K.; Mcbeath, S. Fire endurance of steel reinforced fly ash geopolymer concrete elements. Constr. Build. Mater. 2015, 90, 91-98. [CrossRef]

5. Duxson, P.; Provis, J.L.; Lukey, G.C.; Van Deventer, J.S. The role of inorganic polymer technology in the development of 'green concrete'. Cem. Concr. Res. 2007, 37, 1590-1597. [CrossRef]

6. Li, Z.; Ding, Z.; Zhang, Y. Development of sustainable cementitious materials. In Proceedings of the Workshop on Sustainable Development and Concrete Technology, Beijing, China, 20-21 May 2004; pp. 55-76.

7. Bakharev, T.; Sanjayan, J.; Cheng, Y.-B. Resistance of alkali-activated slag concrete to acid attack. Cem. Concr. Res. 2003, 33, 1607-1611. [CrossRef]

8. Rickard, W.D.; Temuujin, J.; van Riessen, A. Thermal analysis of geopolymer pastes synthesised from five fly ashes of variable composition. J. Non-Cryst. Solids 2012, 358, 1830-1839. [CrossRef]

9. Nath, P.; Sarker, P.K. Effect of GGBFS on setting, workability and early strength properties of fly ash geopolymer concrete cured in ambient condition. Constr. Build. Mater. 2014, 66, 163-171. [CrossRef]

10. Kovalchuk, G.; Fernández-Jiménez, A.; Palomo, A. Alkali-activated fly ash: Effect of thermal curing conditions on mechanical and microstructural development-Part II. Fuel 2007, 86, 315-322. [CrossRef]

11. Duxson, P.; Fernández-Jiménez, A.; Provis, J.L.; Lukey, G.C.; Palomo, A.; van Deventer, J.S. Geopolymer technology: The current state of the art. J. Mater. Sci. 2007, 42, 2917-2933. [CrossRef]

12. Nath, P.; Sarker, P.K. Use of OPC to improve setting and early strength properties of low calcium fly ash geopolymer concrete cured at room temperature. Cem. Concr. Compos. 2015, 55, 205-214. [CrossRef]

13. Rovnaník, P. Effect of curing temperature on the development of hard structure of metakaolin-based geopolymer. Constr. Build. Mater. 2010, 24, 1176-1183. [CrossRef]

14. Görhan, G.; Kürklü, G. The influence of the $\mathrm{NaOH}$ solution on the properties of the fly ash-based geopolymer mortar cured at different temperatures. Compos. Part B Eng. 2014, 58, 371-377.

15. Deb, P.S.; Nath, P.; Sarker, P.K. The effects of ground granulated blast-furnace slag blending with fly ash and activator content on the workability and strength properties of geopolymer concrete cured at ambient temperature. Mater. Des. 2014, 62, 32-39. [CrossRef]

16. Khan, M.Z.N.; Shaikh, F.u.A.; Hao, Y.; Hao, H. Synthesis of high strength ambient cured geopolymer composite by using low calcium fly ash. Constr. Build. Mater. 2016, 125, 809-820. [CrossRef]

17. Nematollahi, B.; Sanjayan, J.; Qiu, J.; Yang, E.-H. Micromechanics-based investigation of a sustainable ambient temperature cured one-part strain hardening geopolymer composite. Constr. Build. Mater. 2017, 131, 552-563. [CrossRef]

18. Nematollahi, B.; Sanjayan, J.; Qiu, J.; Yang, E.-H. High ductile behavior of a polyethylene fiber-reinforced one-part geopolymer composite: A micromechanics-based investigation. Arch. Civ. Mech. Eng. 2017, 17, 555-563. [CrossRef]

19. Nematollahi, B.; Sanjayan, J. Influence of type of fiber on tensile performance of one-part "dry-mix" strain hardening geopolymer composite (SHGC). In Proceedings of the 11th Fib International PhD Symposium in Civil Engineering, Technical University of Tokyo, Tokyo, Japan, 29-31 August 2016; pp. 831-838.

20. Nematollahi, B.; Sanjayan, J. Ambient temperature cured one-part engineered geopolymer composite: A sustainable alternative to engineered cementitious composite. In Proceedings of the 9th Rilem International Symposium on Fiber Reinforced Concrete Vancouver, Vancouver, BC, Canada, 19-21 September 2016; pp. 1117-1126.

21. Bong, S.H.; Nematollahi, B.; Nazari, A.; Xia, M.; Sanjayan, J. Method of Optimisation for Ambient Temperature Cured Sustainable Geopolymers for 3D Printing Construction Applications. Materials 2019, 12, 902. [CrossRef]

22. Sugama, T.; Brothers, L.; Van de Putte, T. Acid-resistant cements for geothermal wells: Sodium silicate activated slag/fly ash blends. Adv. Cem. Res. 2005, 17, 65-75. [CrossRef] 
23. Luukkonen, T.; Abdollahnejad, Z.; Yliniemi, J.; Kinnunen, P.; Illikainen, M. One-part alkali-activated materials: A review. Cem. Concr. Res. 2017, 103, 21-34. [CrossRef]

24. Palacios, M.; Houst, Y.F.; Bowen, P.; Puertas, F. Adsorption of superplasticizer admixtures on alkali-activated slag pastes. Cem. Concr. Res. 2009, 39, 670-677. [CrossRef]

25. Nematollahi, B.; Sanjayan, J. Effect of different superplasticizers and activator combinations on workability and strength of fly ash based geopolymer. Mater. Des. 2014, 57, 667-672. [CrossRef]

26. Yamada, K.; Ogawa, S.; Hanehara, S. Controlling of the adsorption and dispersing force of polycarboxylate-type superplasticizer by sulfate ion concentration in aqueous phase. Cem. Concr. Res. 2001, 31, 375-383. [CrossRef]

27. Björnström, J.; Chandra, S. Effect of superplasticizers on the rheological properties of cements. Mater. Struct. 2003, 36, 685-692. [CrossRef]

28. Puertas, F.; Santos, H.; Palacios, M.; Martínez-Ramírez, S. Polycarboxylate superplasticiser admixtures: Effect on hydration, microstructure and rheological behaviour in cement pastes. Adv. Cem. Res. 2005, 17, 77-89. [CrossRef]

29. Gołaszewski, J.; Szwabowski, J. Influence of superplasticizers on rheological behaviour of fresh cement mortars. Cem. Concr. Res. 2004, 34, 235-248. [CrossRef]

30. Chandra, S.; Björnström, J. Influence of cement and superplasticizers type and dosage on the fluidity of cement mortars-Part I. Cem. Concr. Res. 2002, 32, 1605-1611. [CrossRef]

31. Chandra, S.; Björnström, J. Influence of superplasticizer type and dosage on the slump loss of Portland cement mortars-Part II. Cem. Concr. Res. 2002, 32, 1613-1619. [CrossRef]

32. Palacios, M.; Puertas, F. Effect of superplasticizer and shrinkage-reducing admixtures on alkali-activated slag pastes and mortars. Cem. Concr. Res. 2005, 35, 1358-1367. [CrossRef]

33. Criado, M.; Palomo, A.; Fernández-Jiménez, A.; Banfill, P. Alkali activated fly ash: Effect of admixtures on paste rheology. Rheol. Acta 2009, 48, 447-455. [CrossRef]

34. Nematollahi, B.; Sanjayan, J. Efficacy of available superplasticizers on geopolymers. Res. J. Appl. Sci. Eng. Technol. 2014, 7, 1278-1282. [CrossRef]

35. Nematollahi, B.; Sanjayan, J. Effect of superplasticizers on workability of fly ash based geopolymer. In InCIEC 2013; Springer: Berlin/Heidelberg, Germany, 2014; pp. 713-719.

36. Luukkonen, T.; Abdollahnejad, Z.; Ohenoja, K.; Kinnunen, P.; Illikainen, M. Suitability of commercial superplasticizers for one-part alkali-activated blast-furnace slag mortar. J. Sustain. Cem. Based Mater. 2019, 8, 1-14. [CrossRef]

37. Alrefaei, Y.; Wang, Y.-S.; Dai, J.-G.J.C.; Composites, C. The effectiveness of different superplasticizers in ambient cured one-part alkali activated pastes. Cem. Concr. Compos. 2019, 97, 166-174. [CrossRef]

38. Ramachandran, V.; Lowery, M. Conduction calorimetric investigation of the effect of retarders on the hydration of Portland cement. Thermochim. Acta 1992, 195, 373-387. [CrossRef]

39. Singh, N.; Singh, A.; Singh, S.P. Effect of citric acid on the hydration of Portland cement. Cem. Concr. Res. 1986, 16, 911-920. [CrossRef]

40. Boncukcuoğlu, R.; Yılmaz, M.T.; Kocakerim, M.M.; Tosunoğlu, V. Utilization of borogypsum as set retarder in Portland cement production. Cem. Concr. Res. 2002, 32, 471-475. [CrossRef]

41. Papageorgiou, A.; Tzouvalas, G.; Tsimas, S. Use of inorganic setting retarders in cement industry. Cem. Concr. Compos. 2005, 27, 183-189. [CrossRef]

42. Kavas, T.; Olgun, A.; Erdogan, Y. Setting and hardening of borogypsum-Portland cement clinker-fly ash blends. Studies on effects of molasses on properties of mortar containing borogypsum. Cem. Concr. Res. 2005, 35, 711-718. [CrossRef]

43. Altun, İ.A.; Sert, Y. Utilization of weathered phosphogypsum as set retarder in Portland cement. Cem. Concr. Res. 2004, 34, 677-680. [CrossRef]

44. Kusbiantoro, A.; Ibrahim, M.S.; Muthusamy, K.; Alias, A. Development of sucrose and citric acid as the natural based admixture for fly ash based geopolymer. Procedia Environ. Sci. 2013, 17, 596-602. [CrossRef]

45. Liu, H.; Sanjayan, J.G.; Bu, Y. The application of sodium hydroxide and anhydrous borax as composite activator of class F fly ash for extending setting time. Fuel 2017, 206, 534-540. [CrossRef]

46. Garg, N.; White, C.E. Mechanism of zinc oxide retardation in alkali-activated materials: An in situ X-ray pair distribution function investigation. J. Mater. Chem. A 2017, 5, 11794-11804. [CrossRef] 
47. Gong, C.; Yang, N. Effect of phosphate on the hydration of alkali-activated red mud-slag cementitious material. Cem. Concr. Res. 2000, 30, 1013-1016. [CrossRef]

48. Chang, J. A study on the setting characteristics of sodium silicate-activated slag pastes. Cem. Concr. Res. 2003, 33, 1005-1011. [CrossRef]

49. Brough, A.; Holloway, M.; Sykes, J.; Atkinson, A. Sodium silicate-based alkali-activated slag mortars: Part II. The retarding effect of additions of sodium chloride or malic acid. Cem. Concr. Res. 2000, 30, 1375-1379. [CrossRef]

50. Oderji, S.Y.; Chen, B.; Shakya, C.; Ahmad, M.R.; Shah, S.F.A.J.C.; Materials, B. Influence of superplasticizers and retarders on the workability and strength of one-part alkali-activated fly ash/slag binders cured at room temperature. Constr. Build. Mater. 2019, 229, 116891. [CrossRef]

51. Hardjito, D.; Wallah, S.E.; Sumajouw, D.M.; Rangan, B.V. On the development of fly ash-based geopolymer concrete. Mater. J. 2004, 101, 467-472.

52. ASTM C1437-15. Standard Test Method for Flow of Hydraulic Cement Mortar; ASTM International: West Conshohocken, PA, USA, 2015.

53. AS/NZS 2350.4:2006. Methods of Testing Portland, Blended and Masonry Cements; Standards Australia: Sydney, Australia; Wellington, New Zealand, 2006.

54. AS 1012.9:2014. Methods of Testing Concrete; Standards Australia: Sydney, Australia, 2014.

55. Wallevik, J.E. Relationship between the Bingham parameters and slump. Cem. Concr. Res. 2006, 36, $1214-1221$. [CrossRef]

56. Laskar, A.I. Correlating slump, slump flow, vebe and flow tests to rheological parameters of high-performance concrete. Mater. Res. 2009, 12, 75-81. [CrossRef]

57. Palacios, M.; Puertas, F. Stability of superplasticizer and shrinkage-reducing admixtures Stability of superplasticizer and shrinkage-reducing admixtures in high basic media. Mater. Constr. 2004, 54, 65-86.

58. Komljenović, M.; Baščarević, Z.; Bradić, V. Mechanical and microstructural properties of alkali-activated fly ash geopolymers. J. Hazard. Mater. 2010, 181, 35-42. [CrossRef]

59. Nadoushan, M.J.; Ramezanianpour, A.A. The effect of type and concentration of activators on flowability and compressive strength of natural pozzolan and slag-based geopolymers. Constr. Build. Mater. 2016, 111, 337-347. [CrossRef]

60. Chindaprasirt, P.; De Silva, P.; Sagoe-Crentsil, K.; Hanjitsuwan, S. Effect of $\mathrm{SiO}_{2}$ and $\mathrm{Al}_{2} \mathrm{O}_{3}$ on the setting and hardening of high calcium fly ash-based geopolymer systems. J. Mater. Sci. 2012, 47, 4876-4883. [CrossRef]

61. Ramachandran, V.S. Concrete Admixtures Handbook: Properties, Science and Technology; William Andrew: Park Ridge, NJ, USA, 1996.

62. Yip, C.; Van Deventer, J. Microanalysis of calcium silicate hydrate gel formed within a geopolymeric binder. J. Mater. Sci. 2003, 38, 3851-3860. [CrossRef]

63. Sakulich, A.R.; Anderson, E.; Schauer, C.; Barsoum, M.W. Mechanical and microstructural characterization of an alkali-activated slag/limestone fine aggregate concrete. Constr. Build. Mater. 2009, 23, 2951-2957. [CrossRef]

64. Askarian, M.; Tao, Z.; Samali, B.; Adam, G.; Shuaibu, R. Mix composition and characterisation of one-part geopolymers with different activators. Constr. Build. Mater. 2019, 225, 526-537. [CrossRef]

65. Puertas, F.; Fernández-Jiménez, A. Mineralogical and microstructural characterisation of alkali-activated fly ash/slag pastes. Cem. Concr. Compos. 2003, 25, 287-292. [CrossRef]

66. Singh, B.; Ishwarya, G.; Gupta, M.; Bhattacharyya, S. Geopolymer concrete: A review of some recent developments. Constr. Build. Mater. 2015, 85, 78-90. [CrossRef]

67. Bagheri, A.; Nazari, A.; Sanjayan, J.G.; Rajeev, P.; Duan, W. Fly ash-based boroaluminosilicate geopolymers: Experimental and molecular simulations. Ceram. Int. 2017, 43, 4119-4126. [CrossRef]

68. Plank, J.; Winter, C. Competitive adsorption between superplasticizer and retarder molecules on mineral binder surface. Cem. Concr. Res. 2008, 38, 599-605. [CrossRef]

69. Zhang, G.; Li, G.; Li, Y. Effects of superplasticizers and retarders on the fluidity and strength of sulphoaluminate cement. Constr. Build. Mater. 2016, 126, 44-54. [CrossRef] 
70. Tan, H.; Guo, Y.; Zou, F.; Jian, S.; Ma, B.; Zhi, Z. Effect of borax on rheology of calcium sulphoaluminate cement paste in the presence of polycarboxylate superplasticizer. Constr. Build. Mater. 2017, 139, 277-285. [CrossRef]

71. Tan, H.; Zou, F.; Ma, B.; Guo, Y.; Li, X.; Mei, J. Effect of competitive adsorption between sodium gluconate and polycarboxylate superplasticizer on rheology of cement paste. Constr. Build. Mater. 2017, 144, 338-346. [CrossRef]

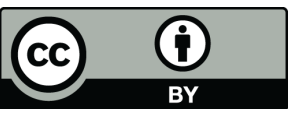

(C) 2019 by the authors. Licensee MDPI, Basel, Switzerland. This article is an open access article distributed under the terms and conditions of the Creative Commons Attribution (CC BY) license (http://creativecommons.org/licenses/by/4.0/). 